Brit. Heart J., 1965, 27, 879.

\title{
AN X-RAY MICROSCOPIC STUDY OF THE ARTERIAL SUPPLY TO THE CONDUCTING SYSTEM OF THE HUMAN HEART
}

\author{
BY \\ JOHN A. CLARKE* \\ From the Department of Anatomy, University of Glasgow, Glasgow W.2 \\ Received March 1, 1965
}

The numerous descriptive and embryological studies carried out on the sinu-atrial and atrioventricular conducting system of the heart in man and animals have been concerned principally with its structure, distribution, innervation, and development. Amongst these, the investigations of Blair and Davies (1935), Walls (1947), Baird and Robb (1950), Field (1951), Glomset and Cross (1952), Truex, Bishof, and Hoffman (1958), and Titus, Daugherty, and Edwards (1963) may be mentioned. More recently Carbonell (1956) isolated the conducting system of the heart by demonstrating the activity of esterases with histochemical techniques, and Lev, Benjamin, and White (1958) reported a histopathological study on the conducting system in a heart with complete block of 42 years' duration. Titus, Neufeld, and Edwards (1964) reported on three cases in which the pulmonary trunk and ascending aorta originated from the right ventricle and showed that the conducting system had been displaced dorsally.

Little reference, however, could be found in the reports to the pattern and distribution of arterioles and capillaries in the conducting system of the human heart. Schlesinger (1938) and Fulton (1963) demonstrated the distribution of the coronary arteries in man after the injection of radioopaque media, but the resolution of the x-ray technique did not allow the visualization of capillaries, and no mention is made of any special distribution of vessels to the conducting system. The pattern of blood supply to the sinu-atrial node in the dog has been described as coming from the right coronary artery (Meek, Keenan, and Theisen, 1929; Moore, 1930; Pianetto, 1939; Kazzaz and Shanklin, 1950), and Halpern (1954) described additional branches being distributed to the node from the left coronary artery and right internal mammary artery. In man, Last (1963) states, without further amplification, that the sinu-atrial node is supplied by a branch of the right coronary artery in 60 per cent of cases, and that the atrio-ventricular node and bundle of His are supplied by a branch of the left coronary artery in 90 per cent.

This work presents an account of the pre-capillary arteriole and capillary pattern of distribution in the sinu-atrial node and atrio-ventricular conducting system of the human heart, using the Coslett Nixon X-Ray Projection Microscope. This gives an opportunity for investigating unfixed, fullthickness preparations without histological intervention, in contrast to the routine staining, injection, and clearing techniques for examining capillary beds by previous investigators (Pickworth, 1934; Williams, 1948; Scharrer, 1950; Woerner, 1959).

* Present address: Department of Anatomy, St. Bartholomew's Hospital Medical School, London E.C.1. 


\section{MATERIAL AND Methods}

Fifty normal hearts were examined within 12 hours of death in equally distributed groups between the ages of 15 and 80 years.

All the specimens investigated had a negative clinical history of cardiac disorder, no arrhythmias, and were free of any discernible lesion at necropsy.

The arterial distribution to the conducting system was shown by injecting micropaque (particulate diameter $0.5 \mu$ or less) through the ascending aorta at manometrically controlled physiological pressures.

The sinu-atrial region of the human heart was selected so as to include more than half of the upper half of the sulcus terminalis, and the adjacent parts of the right atrial and sinus walls and the entry of the superior vena cava.

The specialized atrio-ventricular connexions in the heart included adjacent parts of the interatrial and interventricular septa, the entry of the coronary sinus, and the region in front of the pars membranacea septi.

The microscope was operated at $15 \mathrm{kV}$ and 25 microamperes with a copper target providing the $\mathrm{x}$-radiation. The micrographs were recorded on Ilford Contrasty Plates with an exposure time of 10 minutes.

Capillary densities were estimated by superimposing a radio-opaque mesh on the specimen when the micrograph was taken (200 squares per inch). All the vessels of capillary size were counted in each square, the density measurement being the total number of vessels in all the squares divided by the number of squares.

The provision of controls for the micrographs was attempted by staining the conducting tissue with hæmatoxylin and eosin, van Gieson's stain for connective tissue, Masson's trichrome stain, and Mallory-Heidenhain's stain for sharp differentiation of muscle. These sections resulted in repeated production of tissue with poor tinctorial quality, and easy recognition of conducting areas was difficult. It was decided, therefore, to demonstrate the conducting tissue by staining the rich nervous components of the system, and this was done by the Bielschowsky-Abraham silver impregnation technique.

\section{Results of Radiological ObSERvations}

Sinu-atrial Node. Examination of the micrographs from the upper end of the crista terminalis showed an irregular plexus of arterioles, $100-350 \mu$ in diameter. From this arterial network branches were distributed to the sinus part of the right atrium in an irregular pattern, a count of 7 capillaries per square of the mesh being made. Close to the upper part of the sulcus terminalis, however, an area was found in which the capillary count was increased to 12 capillaries per square of the mesh (Fig. 1). This area possessed an upper and lower extension: the upper being above and in front of the point of entry of the superior vena cava, the lower being traceable to the middle of the sulcus terminalis.

Of the 50 nodes examined, 35 were supplied by the branches of the right coronary artery.

Atrio-ventricular Node. It was clear from the micrographs that an irregular plexus of pre-capillary arterioles and capillaries lay around the entry of the coronary sinus ostium, a count of 7 capillaries per square of the mesh being made. An oval or fan-shaped area, however, was demonstrated immediately above or partly overriding the attachment of the commissure between the posterior and septal cusp of the tricuspid valve in which the capillary count was raised to 10 capillaries per square of the mesh (Fig. 2).

Of the 50 nodes examined, 45 were supplied by the right coronary artery.

Atrio-ventricular Bundle. In the vicinity of the atrio-ventricular bundle the micrographs showed a series of parallel pre-capillary arterioles which originated at the anterior margin of the atrioventricular node, traversed the junction of the posterior extent of the membranous septum and the annuli fibrosæ of the mitral and tricuspid valves, and entered the lower part of the membranous septum. At the point above the centre of the muscular part of the interventricular septum this parallel arrangement of pre-capillary arterioles terminated and entered into an irregular plexus of capillaries (Fig. 3). The capillary count in the atrio-ventricular bundle was 10 capillaries per square of the mesh.

\section{Results of Histological Observations}

In general the histological observations on the conducting areas of the heart confirmed the area distribution of the altered arterial patterns, showing the routine histological appearance of nerve fibres with a silver technique for this area (Fig. 4). 
All micrographs are of full-thickness specimens. Long axis of sinu-atrial, atrio-ventricular nodes, and atrioventricular bundle (1-a).

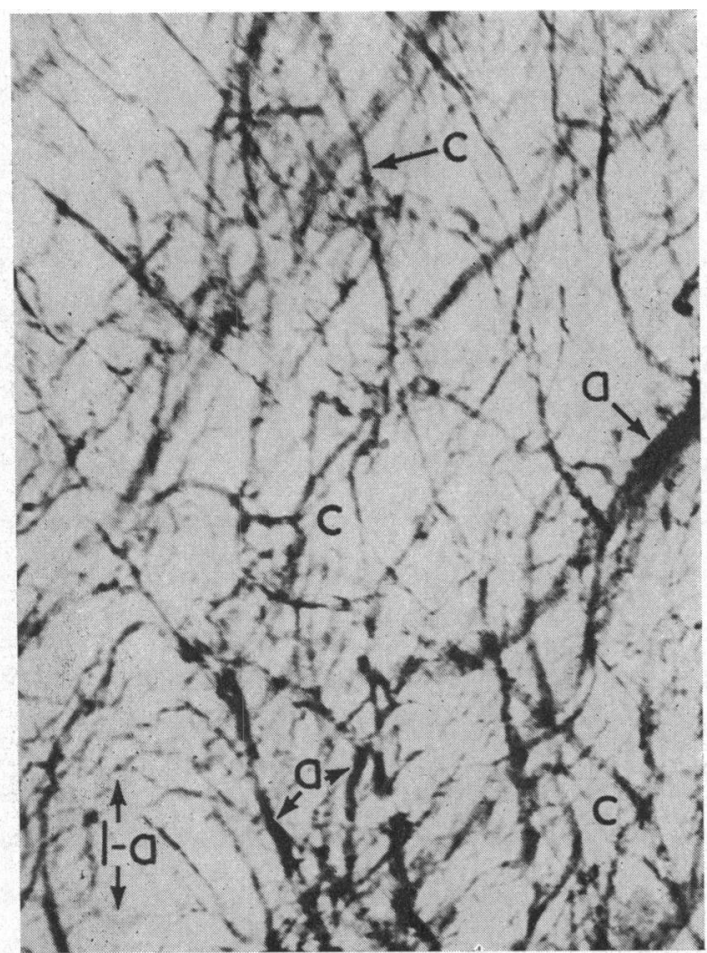

Fig. 1.-Micrograph of full thickness sinu-atrial node. Note the irregular dense network of pre-capillary arterioles (a) and capillaries (c). ( $\times 92$.

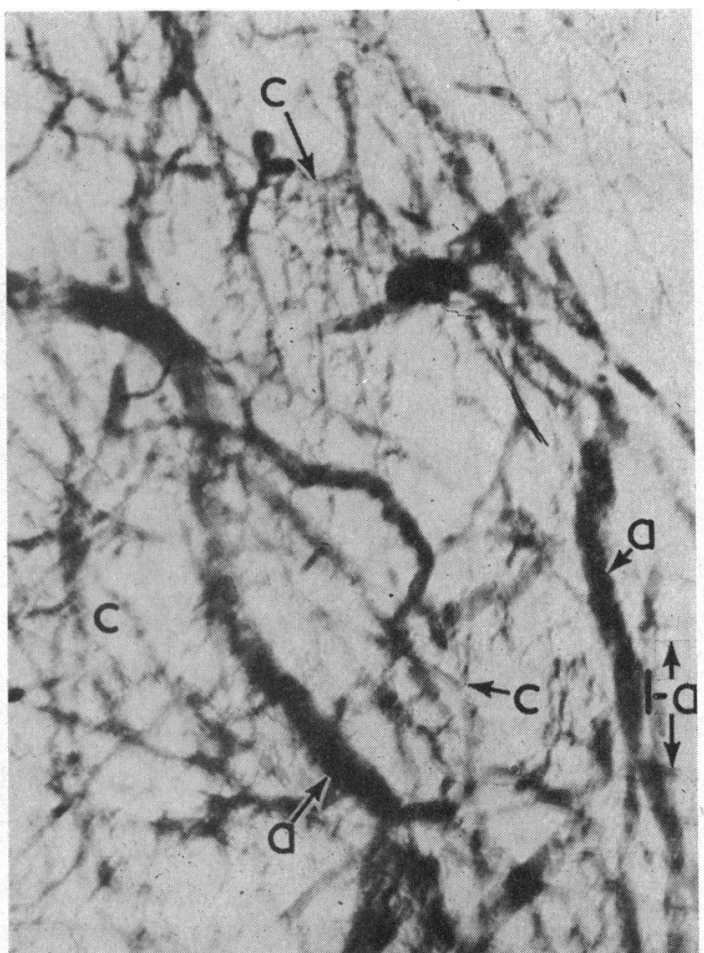

FIG. 2.-Micrograph of full-thickness atrio-ventricular node, showing the irregular plexus of pre-capillary arterioles (a) and capillaries (c). ( $\times 92$.

\section{DisCUSSION}

The technical difficulties encountered in demonstrating the patterns of pre-capillary arterioles and capillaries constitute a limiting factor in studying the vessels in the conducting tissue of the human heart.

X-ray microscopy presents a method that circumvents some of these problems. Its advantage is that unfixed material can be examined in full-thickness preparations with the visualization of small arterioles and capillaries. In this study the particulate diameter of micropaque, which was $0.5 \mu$ or less, allowed the pre-capillary arterioles and capillaries to be filled, and at the same time provided an injection medium that was sufficiently radio-opaque to provide contrast. Under the pressures utilized, the injection entered the small arterioles and capillaries supplying the conducting tissue and did not extravasate into the wall of the heart frequently.

On the other hand the technique depends upon an injection method with all the hazards of incomplete filling of the vessels, and an area reported as less vascular may be regarded as one that has not accepted the injection mass completely. In this work the criterion for accepting an area as less vascular was the repeated production of an arterial picture and subsequent capillary count under conditions that filled capillary beds to a greater effect elsewhere in the same specimen constantly.

Staining methods are particularly suitable for investigating adaptive changes in vascular patterns under varying conditions, giving a true picture of the state of the circulation at that time (Pick- 


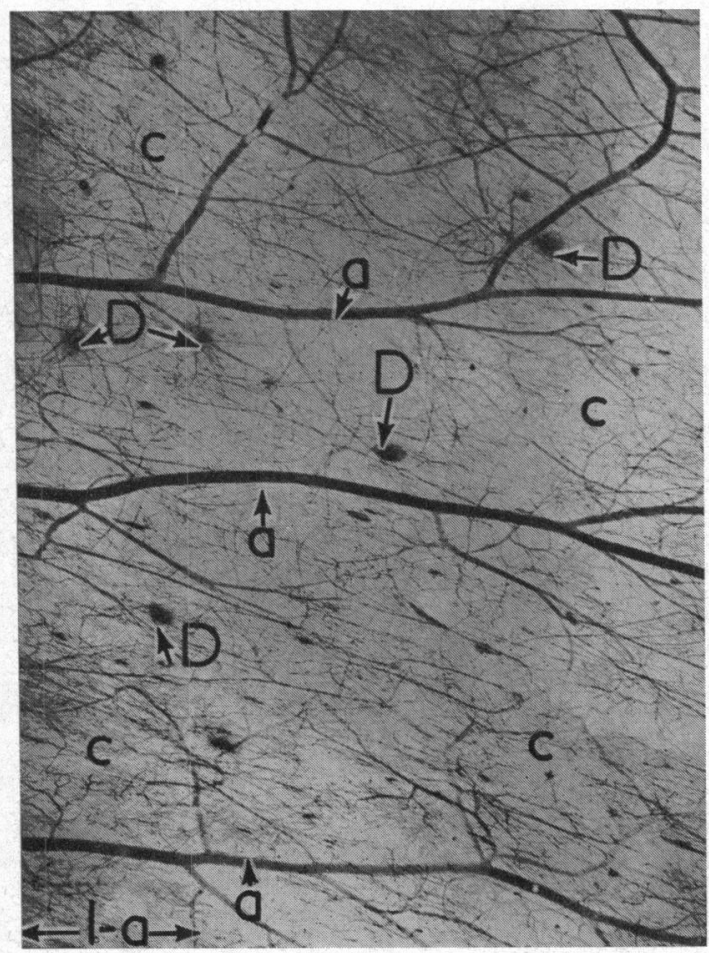

Fig. 3.-Micrograph of the full thickness atrioventricular bundle. Note the parallel arrangement of pre-capillary arterioles (a) and irregular plexus of capillaries (c). Extravasations of micropaque (D). $(\times 45$.

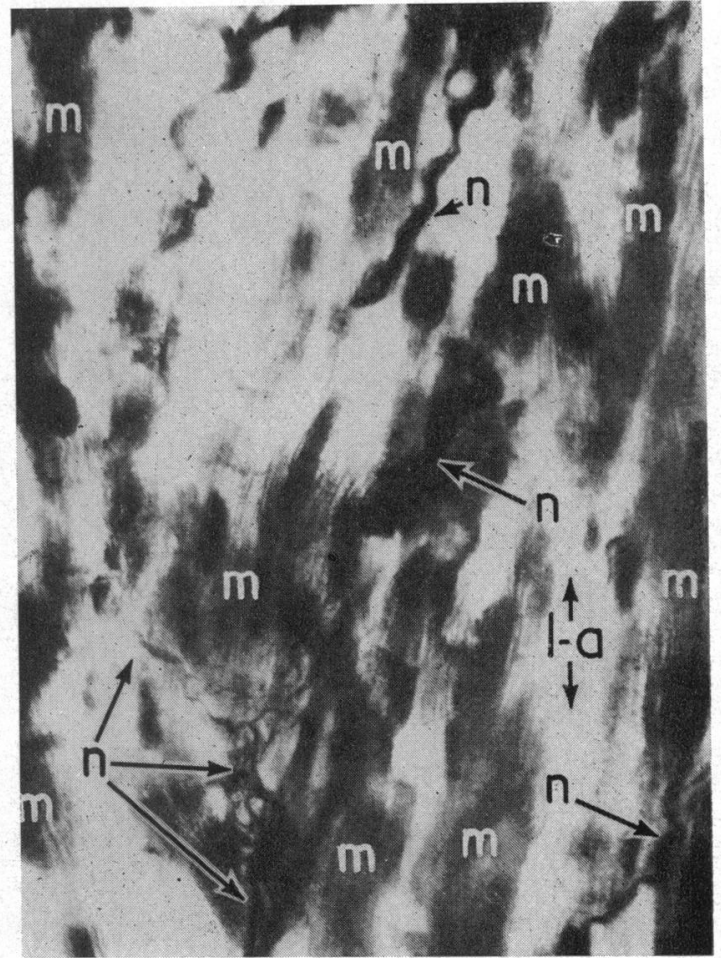

FIG. 4.-Photomicrograph of $40 \mu$ thick section of the atrio-ventricular node. Note the plexus of nerves (n) being distributed among the cardiac muscle fibres (m) (Bielschowsky-Abraham stain. $\times 368$.)

worth, 1934; Scharrer, 1950). Injection methods, in contrast, intend to present the vascular pattern at its maximum capacity, and are suited to purely anatomical investigations. For this reason, along with the technical advances of $\mathrm{x}$-ray microscopy, the arterial patterns in the conducting tissue of the human heart were studied by this method.

The present study has demonstrated that there is an extensive arterial supply to the sinu-atrial node and atrio-ventricular node and bundle.

Observations on the arterial supply to adult nodal tissue in the conducting system of the heart are usually confined to a description of the origin or presence of a nodal artery (Last, 1963; Titus et al., 1963), while in human fotal material Walls (1947; reported that a nodal artery was shown in the sinu-atrial node after $16.5 \mathrm{~mm}$. and that at $25 \mathrm{~mm}$. "capillary blood vessels are becoming numerous".

As indicated by the x-ray microscope the characteristic arterial pattern in the sinu-atrial and atrioventricular nodes was that of an irregular plexus of pre-capillary arterioles and capillaries, the capillary count being higher in the sinu-atrial node. In a previous communication (Clarke, 1965) the normal atrial patterns in human atria were described, and capillary counts of seven vessels per square of the mesh in the sinus part of the right atrium were recorded. It appears from the micrographs, therefore, that the capillary counts in the sinu-atrial and atrio-ventricular nodes are higher than at any other site in the atrium. In this study the arterial supply to the sinu-atrial node originated from the right coronary artery in $\mathbf{7 0}$ per cent of specimens and from the right coronary artery to the atrio-ventricular node in 90 per cent. 
The atrio-ventricular bundle had a characteristic arterial picture which consisted of parallel precapillary arterioles, a count of 10 capillaries per square of the mesh being recorded. This calculation of capillary density was the same as that for the atrio-ventricular node but slightly less than that for the sinu-atrial node.

In this study, as indicated by the x-ray microscope, there was no alteration with age in the capillary density in any part of the conducting system.

No attempt was made to trace the conducting tissue further than the division of the common atrio-ventricular bundle, since the thickness of the specimen prevented an examination of fullthickness preparations, and since it was found that definite identification of conducting tissue was difficult beyond this point.

\section{SUMMARY}

The pattern and distribution of pre-capillary arterioles and capillaries to the conducting tissue of the human heart was studied with the Coslett Nixon X-Ray Projection Microscope.

An irregular plexus of pre-capillary arterioles and capillaries was found in the sinu-atrial and ventricular nodes.

A parallel arrangement of pre-capillary arterioles was found in the common atrio-ventricular bundle.

The capillary density was greatest in the sinu-atrial node.

I am indebted to the Medical Research Council, who gave the x-ray microscope to the Anatomy Department, University of Glasgow.

\section{REFERENCES}

Baird, J. A., and Robb, J. S. (1950). Study, reconstruction and gross dissection of the atrioventricular conducting system of the dog heart. Anat. Rec., 108, 747.

Blair, D. M., and Davies, F. (1935). Observations on the conducting system of the heart. J. Anat. (Lond.), 69, 303. Carbonell, L. M. (1956). Esterases of the conductive system of the heart. J. Histochem. Cytochem., 4, 87.

Clarke, J. A. (1965). An X-ray microscopic study of the pattern and distribution of capillaries in the atria of the human heart. Z. Anat. Entwickl.-Gesch. In the press.

Field, E. J. (1951). The development of the conducting system in the heart of sheep. Brit. Heart J., 13, 129.

Fulton, W. F. M. (1963). Immersion radiography of injected specimens. Brit.J. Radiol., 36, 685 .

Glomset, D. J., and Cross, K. R. (1952). Morphologic study of the cardiac conduction system. Part 6. The intrinsic nervous system of the heart. A.M.A. Arch. intern. Med., 89, 923.

Halpern, M. H. (1954). Arterial supply to the nodal tissue in the dog heart. Circulation, 9, 547.

Kazzaz, D., and Shanklin, W. M. (1950). The coronary vessels of the dog demonstrated by colored plastic (viny lacetate) injections and corrosions. Anat. Rec., 107, 43.

Last, R. J. (1963). Anatomy, Regional and Applied, 3rd ed. Churchill, London.

Lev, M., Benjamin, J. E., and White, P. D. (1958). A histopathologic study of the conduction system in a case of complete heart block of 42 years' duration. Amer. Heart J., 55, 198.

Meek, W. J., Keenan, M., and Theisen, H. J. (1929). The auricular blood supply in the dog. I. General auricular supply with special reference to the sino-auricular node. Amer. Heart J., 4, 591.

Moore, R. A. (1930). The coronary arteries of the dog. Amer. Heart J., 5, 743.

Pianetto, M. B. (1939). The coronary arteries of the dog. Amer. Heart J., 18, 403.

Pickworth, F. A. (1934). A new method of study of the brain capillaries and its application to the regional localisation of mental disorder. J. Anat. (Lond.), 69, 62.

Scharrer, E. (1950). A technique for the demonstration of the blood vessels in the developing central nervous system. Anat. Rec., 107, 319.

Schlesinger, M. J. (1938). An injection plus dissection study of coronary artery occlusions and anastomoses. Amer. Heart J., 15, 528 .

Titus, J. L., Daugherty, G. W., and Edwards, J. E. (1963). Anatomy of the normal human atrioventricular conduction system. Amer. J. Anat., 113, 407.

-, Neufeld, H. N., and Edwards, J. E. (1964). The atrioventricular conduction system in hearts with both great vessels originating from the right ventricle. Amer. Heart J., 67, 588.

Truex, R. C., Bishof, J. K., and Hoffman, E. L. (1958). Accessory atrioventricular muscle bundles of the developing human heart. Anat. Rec., 131, 45.

Walls, E. W. (1947). The development of the specialized conducting tissue of the human heart. J. Anat. (Lond.), 81, 93.

Williams, T. W. (1948). The visualization of vertebrate capillary beds by intravascular precipitation of lead chromate. Anat. Rec., 100, 115 .

Woerner, C. A. (1959). In The Arterial Wall, Ed. A. I. Lansing, pp. 1-14. Williams and Wilkins, Baltimore. 